Library Collections, Acquisitions, \& Technical Services, 2000, Vol. 24, Issue. 3, p.391- 402.

ISSN: 1464-9055

http://www.sciencedirect.com/science/journal/14649055

http://www.sciencedirect.com/science/journal/14649055/24/3

http://www.sciencedirect.com/science/article/pii/S1464905500001342

http://dx.doi.org/10.1016/S1464-9055(00)00134-2

(C) 2000 Elsevier B.V. All rights reserved

\title{
Highlights of the second European ScienceDirect User Conference
}

\author{
Carol Pitts Diedrichs
}

\section{Introduction}

"Integration and Linking" was the theme of the Second European ScienceDirect User Conference held September 16-17, 1999, in Amsterdam, The Netherlands. A North American ScienceDirect User Conference was held in New York around the same time. Science-Direct is the electronic journals platform from Elsevier Science which includes all Elsevier titles but also those of other publishers. The conference was opened with remarks from Eric de Wilde (Director of the Regional Sales Office for Europe, the Middle East and Africa, Elsevier Science) and Pat Sabosik (Vice President and General Manager, ScienceDirect). de Wilde stated that Elsevier Science is dedicated to electronic media and a long future with its customers in this market. Currently, 20\% of Elsevier's customers are using ScienceDirect heading toward 30\% by the end of 1999. Sabosik indicated her pride at being associated with a product which is changing the way scientists do their work. ScienceDirect, Elsevier's leading product, is a partnering between librarians, publishers and authors. For example, there were 7 million requests for information within the Web service in August 1999 alone. Elsevier wondered when they were building and designing the system whether anyone would use it. Obviously, they do and will.

\section{E-journals: the OhioLINK Experience-Carol Pitts Diedrichs, Assistant Director for Technical Services, The Ohio State University Libraries}

Diedrichs opened with a description of OhioLINK, a consortium of Ohio's college and university libraries and the State Library of Ohio. Serving more than 500,000 students, faculty, and staff at 76 institutions, OhioLINK offers access to more than 31 million library items statewide. The OhioLINK central catalog also supports the intrastate borrowing of book and audiovisual materials among the member libraries. Building on this efficiency for the delivery of books, OhioLINK needed to find a solution for the delivery of articles from journals. OhioLINK wanted to address three basic problems: the rapidly increasing costs of journal subscriptions; the availability of 30+ citation databases through OhioLINK was generating greater demand for actual textual material (requests for journal articles via OCLC's ILL system were running 15-20\% over the previous year); and expanding the OhioLINK model of supplying the journal literature from the collections around the state would result in significant questions about adherence to copyright and fair use guidelines. The key solution proposed was to obtain licenses for journal use on a 
statewide basis at the publisher level maximizing the power and size of OhioLINK.

The first contract signed for the OhioLINK Electronic Journal Center (EJC) was in 1996 with Academic Press for 175 titles. That contract was followed by a three year contract with Elsevier in 1997 for 1,100 titles. The concept of the EJC included mounting these journals locally and providing links to citation databases, the OhioLINK central catalog, and to local catalogs. An electronic version of each journal is stored on OhioLINK servers and is accessible using Orion Scientific Systems software search interface. As of September 1999, the EJC currently had more than 1,300 journal titles from Academic Press, Elsevier, Johns Hopkins University Press (Project Muse), Kluwer, and Springer-Verlag. OhioLINK is not a participant in Elsevier's ScienceDirect aggregator service. Instead, OhioLINK negotiates independently with each publisher and then loads the data to local servers which serve only OhioLINK libraries.

Diedrichs next spoke in more general terms about how to anchor the existence and easy availability of full-text journals in the minds of researchers, teachers and students. Librarians seem to know most about what researchers, teachers and students want as users. Publishers seem to know the most about these same people as authors. The scientist as author does not have the same viewpoint as the scientist as user and habits vary considerably from discipline to discipline [1].

In preparation for discussing the usage of the OhioLINK e-journal system, Diedrichs discussed usage data from various recent projects. Measuring the use of print journals has always been, if not impossible, so staff intensive as to be impractical. Providing journals in electronic format offers the opportunity to study usage in a more systematic way. The data can be used to gauge low and high use titles and to inform budgetary and selection decisions. Most of the usage studies of electronic journals have occurred in the latter 1990s once a concentration of e-journals was made available to users. These studies reveal conflicting results and conclusions drawn from the data gathered. For example, one study will tell you that "users look for articles not journals" [2] while another will tell you that."...browsing of the issue still has significant value. The concept of the journals is still valid as more than a random collection of articles." [3]

With those general and somewhat conflicting findings in mind, Diedrichs turned the attention to the OhioLINK EJC specifically. The initial database of Academic Press and Elsevier titles was introduced in April 1998. The initial file also included data from 1995 and 1996 backfiles as well as current 1997 issues. Since service began in April 1998, over 400,000 articles representing virtually all of the 1,345 titles have been downloaded. In the first 12 months, the universities in OhioLINK averaged $48 \%$ of articles and $70 \%$ of titles downloaded that were NOT held in print at the patrons' local institution [4]. In looking at Ohio State University in particular, "From July 1998 through June 1999, Ohio State personnel downloaded more than 92,000 articles from [the EJC] . . . ; approximately one fourth of the usage has been from titles to which we did not previously have access." [5] At the beginning of the license, OSU held 782 titles in print (656 from Elsevier, 126 from Academic). As the largest library in OhioLINK, OSU's print holdings at 59\% were the most extensive. The next closest library was the University of Cincinnati at $46 \%$. The average percentage holdings among the 15 research institutions in OhioLINK was only $27 \%$. During the first year, Ohio State users downloaded articles from 1,270 titles held in the EJC; 761 of those were also held in pint, 509 titles were not previously held in print. During this time period, OSU patrons downloaded 74,512 individual articles from the EJC; 53,972 were from titles previously held in print, 20,540 were from titles not held in print. Of those 20,540 downloaded articles from titles not held in print, 18,262 would have been over the fair use rule of 5. From a percentage perspective, $40 \%$ of the titles downloaded were not held in print, $28 \%$ of the articles were from titles not held in print. As you can imagine, for libraries which held many fewer titles in 
print at the outset, their percentage of downloaded articles was even higher. All of the other 14 research institutions saw percentages of titles downloaded which were not held in print of over $50 \%$ and in most case in the $70-80 \%$ range. As a result of this first year's data, Tom Sanville (OhioLINK Executive Director) drew the following conclusions:

- $\quad$ what we have in print is not what we need;

- $\quad$ the expansion in use can be dramatic;

- $\quad$ expansion/integration of the EJC will breed more use; and

- there is strength in diversity and group action.

OhioLINK's successes now far exceed the initial mandate for the project. No one could have envisioned the full-text e-journals and the image and data files being made available at the individual's desktop computer or at home. "OhioLINK's Electronic Journal Center debuted in April 1998 and is designed to provide the Ohio higher education community with desktop access to the vast array of research and scholarly journals. Expanded access to the breadth of current high quality research is necessary to support robust faculty research and high quality instruction in Ohio. Now, Ohio's institutions of higher education can contribute necessary research and innovations to Ohio business and industry, and better prepare Ohio's graduates to work in this technologically advanced environment." [6]

\section{Customer Case Study 1-Torsten Erler-Stelz, Librarian, Schering AG}

Erler-Stelz heads the Information Services and Library (ISL) for Schering AG in Berlin. The purpose of the ISL is to search for and obtain information on any work-related topic, to collect information published worldwide about the company's products, to offer training and advice to those who wish to search on their own and assist in the development of customized literature databases, and to supply all classic library services, such as $24 \mathrm{~h}$ reading rooms, book and journal catalogs, photocopy delivery, book loans, circulation of periodicals, and the purchase of information in printed and electronic form.

In May 1999, the ISL did a survey of 800 researchers with a response rate of approximately $50 \%$. The questions and responses follow:

1. If ISL provided a comprehensive reference library, including access to selected e-journals and Current Awareness systems, would you then be prepared to give up, partly or in total, journals that are circulated to you? Yes (totally) - 20\%; Yes (partially) - 50\%; No - 30\%.

2. Would you accept e-journals which are available in full text via the Internet as a replacement for the hardcopy journals which are currently circulated? Yes (totally) $48 \%$; Yes (partially) - 4\%; No - $48 \%$.

3. Would you accept electronic tables of contents as a replacement for circulated printed issues? Yes - 40\%; No - 60\%.

4. Do you already use table of contents services? If you do, in which form (databases etc.)? Yes - 35\%; No - 65\%. Of the 35\% who answered "yes," most customers use in-house databases, only a few still prefer printed services; acceptance of e-mail alerting services is lower than expected. 
Following the survey, Schering made available from May-August 1999, 169 journals from ScienceDirect in full text. Access is limited to Internet account holders within the company. Access to the Internet is provided to only a small number of employees (less than 1000), mostly those in research and development. During the four month trial, there were 1,200 visits to the journal list. This number is considered impressive given the level of usage of other services they offer.

Erler-Stelz concluded with those things he is happy and unhappy about with ScienceDirect:

\subsection{Contents}

1. Completeness: In principle, all issues published in a journal volume are made available, including supplements (congress abstracts), editorials and letters to the editor. In reality, there are many gaps in the early volumes, especially in the 1996 volume.

2. Currency: The majority of issues are now published simultaneously with the dispatch of the hardcopy issue, some of them even before this. There have been remarkable improvements in currency, when compared with the state of things in early 1999.

3. Comprehensiveness: The number of available e-journals in ScienceDirect has reached a critical mass - customers prefer access from as few portals as possible, ideally from just one.

4. $99 \%$ of all published Elsevier journals have already been made available electronically; at Schering: only 5 out of 169 e-journals they subscribe to are not yet available online.

5. Enhanced Abstracts in SummaryPlus format offering additional access to article outline, thumbnail images, references with links to abstracts (including EMBASE records) are highly appreciated by scientists as a convenient way to check the relevance of an article.

6. Cross-linking from journal references to other full text articles (full text in DocumentPlus format only) is also very popular.

7. Almost all journals are now offering full text in both HTML and True PDF format (for high quality prints).

8. The pay-per-view option allows the purchase of articles from journals that Schering does not currently subscribe to.

9. Journals from competing publishers (e.g., American Institute of Chemical Engineers) are included.

10. There is no inclusion of additional multimedia material (e.g., video sequences, graphics, sounds), so the electronic issue remains an exact mirror of the hardcopy edition (except ads and jobs).

11. Elsevier guarantees availability of archive files for previous volumes, but no technical and financial details have yet been released.

12. There is no convenient alerting service for recently published electronic issues. There is SDI for subject searches but it is not available for specific titles.

13. There is no 'prepublication' service (earliest release of accepted articles) nor has the Digital Object Identifier (DOI) been implemented.

14. There are missing links from references in SummaryPlus abstract to available full text. 
15. There are missing links from the abstract in non-subscribed journals to the document ordering function.

16. Insufficient quality control: incorrect bibliographic entries appear frequently, no immediate correction even after being reported to ScienceDirect.

17. Reported issue gaps are not filled; the immediate feedback only concerns the receipt of the message reporting the gap. This is not followed by information about whether or not corrections have been implemented.

\subsection{Technique}

1. The system is easy to use and intuitive.

2. Access via IP authentication is provided (and preferred).

3. Articles are provided in True PDF format with an HTML equivalent. Color images are also stored in True PDF.

4. There is a reliable link from article references to other full text sources within ScienceDirect (a rival e-journal service links to a PubMed abstract instead of the full text).

5. Personal profiles for customized system setup allow individual access tailoring (e.g., user-specific journal list).

6. There are three different access options for different purposes: account level, department level, and user level.

7. The system permits storage of search queries for individual processing or as an SDI (automatic daily or weekly e-mail alert).

8. Journals lists (either by title or subject) can be limited to display only titles to which the library subscribes; in addition, there are different icons for journals to which the library does and does not subscribe.

9. The system provides content-oriented online help.

10. There are full text links to ScienceDirect journals from Evaluated Medline (BioMed-Net), EMBASE and ISI Web of Science, but such links are still missing for other core databases/services: Chemical Abstracts SciFinder/Chemport, ISI Current Contents Connect, PubMed.

11. Extended statistical information can be provided (e.g., number of full text downloads from journals to which the library does or does not subscribe), but still not on a regular basis.

12. There is only one server site and no server location in Europe. Direct access to New York planned.

13. There is no integration into e-journal meta services provided by subscription agents (e.g., SwetsNet, Laser).

14. There are no full text links to e-journal services from other publishers outside ScienceDirect.

15. Libraries want an alphabetical journal title list with first-last issue data (vol./no./ year).

16. There are previous volumes from almost every journal, especially for publication years 1995-1997, without SummaryPlus, HTML and True PDF format. For the time being full text searches will not cover large parts of the issue set.

17. Limited searches in single journals should be possible. 
18. The Lexis-Nexis search engine cannot differentiate between umlauts and normal vowels.

Sabosik made some clarifying remarks to indicate Elsevier's plans in relationship to the concerns expressed by Erler-Stelz.

1. Elsevier is currently in a trial with Wiley and Springer to test the DOI.

2. Elsevier plans to load Medline links into ScienceDirect in the future.

3. Alerting services are planned for 2000.

4. Elsevier has released its commitment to archiving. They plan to maintain themselves but also have a plan to transfer the archive to a national library should they decide not to maintain at some point in the future.

5. There is no current cost to access the archive but they may charge for that in the future.

Erler-Stelz concluded his remarks with the requirements for users and libraries if e-journal services are to be successful in replacing paper journals.

1. Electronic version has to be complete (all issues, all contributions, maybe advertisements) and available at least at the same time as the printed issue.

2. "Critical mass of titles" has to be reached by an e-journal service, single title offers are only acceptable for core journals (e.g., Science, PNAS).

3. Full text in HTML ('quick browsing', linking) and True PDF (reading, archiving, citation).

4. Uncomplicated access, IP authentication as the most user friendly solution.

5. Cross-linking from online databases, e.g., Medline, Current Contents, Web of Science, EMBASE, Scifinder, Crossfire.

6. Common platform for as many suppliers as possible without loss of functionality.

7. Reliability: Certainty that a service will continue. Archiving cannot be done by a single library. Short term "special offers" are not popular because they require continuous monitoring, and this is a labor and time intensive task.

8. E-journal services have to be affordable and licensed at fair rates especially for models of global company-wide access.

\section{Patterns of usage of full text electronic journals-Jan Molendijk, Account Development Management, Elsevier Science}

Molendijk focused his presentation on patterns of usage. Why does usage matter? Usage is the new metric of journal success. Usage is good for:

1. researchers: better information for their work

2. librarians: higher profile, more "bang for their buck"

3. authors and editors: higher citation rates

4. publishers: higher impact factor

5. ScienceDirect: increased revenue, higher profile

6. Elsevier Science: show value of journal. 
Historically, paper journals provided little data on their usage. The impact of the journal was measured by citations. First, Elsevier implemented a system called Adonis which was a back-office document delivery solution but it had no real end-user data available. Elsevier's first real experience with desktop access came with the TULIP, Elsevier Electronic Subscriptions, and ScienceDirect OnSite products. Each project included detailed logfile analysis and, as a result, usage patterns began to emerge. Today with ScienceDirect OnSite, logfile processing is ongoing and trends are visible. There are a number of challenges in the usage environment. Specifically, trying to consistently define aspects of usage such as user, host, repeat host, download, hit, access and session is very difficult. When proxy servers are used, the system cannot determine who the user is. Consistency is difficult as we learn more. For example, the data may change from year to year making for difficult comparisons. Getting data from ScienceDirect OnSite customers is dependent on users sending the data to Elsevier.

Overall, ScienceDirect usage shows steady growth. Not only do existing users use the system more as they become comfortable with it but there is steady growth in new users. All measures of usage such as number of visits/sessions, number of registered users, and articles requested are growing rapidly. Several overall trends follow:

1. PDF is the most popular format (>75\%), but SummaryPlus is a clear winner in some fields such as organic chemistry

2. Users initiate more but shorter sessions; this is attributed to the use of the OPAC links and the abstracting and indexing layer of access, e.g., the patron already knows he is interested in the article when he gets to the system

3. HTML will gain in popularity as the power of reference linking becomes visible.

The new customer usage growth cycle follows the product-marketing life-cycle. The four stages of this cycle are introduction, growth, maturity and saturation. All of the current ScienceDirect customers are in the introduction or growth stages; thus, there is much room for continued growth through the last two stages. Customers are still dependent on network access on the desktop. The academic year pattern is superimposed over the growth cycle. Users are sensitive to promotion activities such as awareness events and training activities. Most user communities follow a common pattern of introduction, some growth, a small dip in usage and then sustained growth.

ScienceDirect has been designed to provide the following usage statistics: total number of requests, top 10 types of pages accessed, journal browse activity (both subscribed and unsubscribed titles), journal articles and summaries accessed (totals, top 20 subscribed journals, unsubscribed journal access), search activity (basic and advanced), document delivery requests (if you allow access to those you do not subscribe to), user account access, and top 10 help files requested which gives information on where users need help. These usage data are currently provided only on request but Elsevier expects to provide them for everyone in the future.

Molendijk closed with his views on the effects of e-journals on scientific work. On the positive side, users get more: more relevant and more timely information; it is easier to quote accurate references; less time is spent on the logistics of obtaining information, and work is more efficient based on better information. The negative effects include less browsing/ serendipitous searching and the possible diminishing of the social function of the reading room. 


\section{ScienceDirect Future Developments re: Integration and Linking-Pat Sabosik, Vice President and General Manager, ScienceDirect}

Sabosik opened the second day of the conference with a discussion of the current Elsevier Science/ScienceDirect profile. Elsevier Science includes 1,200 titles in 14 disciplines. In addition, the company produces secondary databases such as Compendex, EMBASE and specialty databases such as BioMedNet. ScienceDirect is a platform for distributing scientific information providing institution-wide access to the desktop. Elsevier attempts to make the service reasonably priced and with a high degree of functionality. The company has also made a number of policy changes in the last year including allowing the inclusion of material in course packs at no additional cost when the institution is a subscriber to the service. As mentioned earlier, Elsevier has recently mentioned a new archival policy and their ILL policy has been eased recently. The policy still requires the subscriber to own the paper before loaning but the actual transmission can come from the electronic version.

From the content perspective, ScienceDirect includes integration of primary journal content with a navigational layer of abstracts and indexing. The database is being constructed in SGML format to enhance linking opportunities, e.g., cited references with links to abstracts of the full-text. ScienceDirect has also been designed to be a platform for other publishers' content and other items (newsletters, reference works, reports, datasets), as well as journal articles. Elsevier plans to integrate non-textual material with the journal text such as audio files, film clips, etc. ScienceDirect is also designed to be a gateway strategy to link other content sources and distribution sites.

In Sept. 1999, ScienceDirect included 670,000+ full text journal articles, 2.0+ million abstracts in the database as well as 14+ million abstracts with the combined secondary databases. Third party publishers are also carried on the platform and links exist with ISI's Web of Science, American Mathematical Society's MathSciNet, and Cambridge Scientific Abstracts. Discussions were underway with SilverPlatter. Publishers loaded include: American Institute of Chemical Engineers, CRC Press, Anderson Publishing, and the Royal Society of Medicine.

ScienceDirect is a large-scale Internet solution. If an institution wants a local solution, they can purchase ScienceDirect OnSite which includes document management software developed by ScienceServer. The system uses gateway technology to enable linking between ScienceDirect and various content hosts. There is also a transaction system underlying ScienceDirect for e-commerce activities. A subscription to ScienceDirect includes unlimited access to subscribed journals, current year plus previous three years. The subscriber also has access to the Elsevier Science archives and unlimited access to all tables of contents and abstracts. An institution can purchase access to non-subscribed journals and an option is available for cross-access to non-subscribed journals for consortia. A subscription includes usage reports and internal article linking to abstracts or full-text where available. The system also provides external links to other publishers' journals. The system includes document delivery options for articles not in ScienceDirect and an abstracting and indexing layer for navigation. Finally, a subscription includes account management routines and customer service and training.

General ScienceDirect features include: e-mail alerts from saved searches, relevance ranking for search results, sorting by date, credit card functionality (fourth quarter 1999), reference books, newsletters, reports (fourth quarter 1999 to first quarter 2000), and formula searching (fourth quarter 1999). Specific features designed for the individual scientist include: personal journal list; saved searches; e-mail alerts from saved searches, alerts saved for 30 days; system 
saved last search; e-mail link to author for comments; and credit card purchase of non-subscribed journal articles within the institutional account.

As of August 1999, Science Direct had 780+ institutions and 17 installations of SD OnSite. Twelve agreements had been signed for linking into ScienceDirect and the estimated number of scientists being reached by the system was 4 million worldwide (with a projection of 6 million by the end of 1999). ScienceDirect users were downloading an average of 10.6 articles per user; ScienceDirect OnSite users were downloading an average of 7.4 articles per user. Development efforts for the system are focused on stimulating journal use through linking and integration.

\section{ScienceDirect linking strategies for customers-Ann Gabriel, Marketing Manager, ScienceDirect}

Gabriel focused her presentation on the gateway aspects of ScienceDirect. A gateway is a network point that acts an entrance to another network. The ScienceDirect Gateway is the technology that links abstracts and full text articles from other information providers' Web sites to the online content at ScienceDirect and local content at ScienceDirect on Site. Gateway technology also enables links from abstracts and full text articles on the Science-Direct Web site to external publishers' and service providers' content. The Gateway is a secure system involving an exchange of bibliographic keys to enable linking. Gabriel identified seven objectives of gateway linking:

1. To provide ScienceDirect and ScienceDirect OnSite users with the most comprehensive Web resource for scientific information through the loading and linking of content.

2. To enhance the user experience through seamless linking from the user's preferred interface.

3. To make customers aware of Gateway developments at SD.

4. To make potential partners aware of the opportunities that linking to SD offers.

5. To affirm ScienceDirect's reputation as a publisher at the forefront of technology, and one who is interested in cooperative knowledge exchange with other organizations.

6. To maximize usage of ScienceDirect.

7. To increase the return on the library's investment in ScienceDirect.

Internal linking includes links to full text articles within ScienceDirect from the abstracting and indexing layer. Internal linking also includes links to full text articles within ScienceDirect from cited references with SD articles. External linking involves inward links to ScienceDirect content from A\&I services such as Web of Science, from specialist databases (Math Reviews), from user communities (BioMedNet), from ScienceDirect On-Site, and from library OPACs to the journal title pages. External linking also includes outward links to other service providers' content from the SD full text, from cited references, and from the SD A\&I layer. Gabriel closed her presentation by listing several mutual goals of ScienceDirect and its subscribers: to increase the functionality of library OPACs, to improve navigation for users, to customize the user experience, to increase the value of library investments in bibliographic services, and to extend the reach of the SD platform. 


\section{Customer Case Study 2 - Heidi Bjerremand Mikkelsen, Librarian, Lundbeck $\mathbf{H}$}

A/S

Mikkelsen is the librarian for Lundbeck, a Danish drug company with subsidiaries in 29 countries. Most of the company's research is focused on drugs for central nervous system disorders such as Schizophrenia, depression, anxiety disorder, Alzheimer's disease and Parkinson's disease. As a result, scientific literature is of vital interest to the company's researchers who need the latest research results and news within their field. The Library subscribes to 350 journals: 90 are accessible in electronic full text, 28 of those from ScienceDirect. Since the paper copies of journals are circulated among scientists, distribution time is too long, readers are unsatisfied, and extra use is made of ILL and staff time to acquire articles which are contained in journals still circulating throughout the company. The Library was motivated to solve these issues for the end user as well as the library staff. Providing full text electronically allows faster access to the journal information, provides better search facilities, and better linking facilities. The benefits for the library staff is a reduction in resources used for article request, better service provided to users, and elimination of the problem of mail piling up on individuals' desks.

Lundbeck's implementation strategy was to make the system easy to use, to deliver the journal to the user's mailbox, to mediate all contact with the supplier/vendors, and to force end users to use the electronic version. A letter was sent to each scientist which was customized to include journal titles used by that scientist, the journal's URL address, the coverage of the title, and the mail alert service. Readers were removed from the print routing list as they were notified of the availability of a title electronically. The users are also sent an e-mail alert when a new issue is available including a clickable link to the text. The electronic journals were promoted with new employees. The next steps will include an expansion of their user education program to include a general introduction to electronic journals. In addition, they hope to open direct access to unsubscribed journals to the end user; currently, library staff must initiate those requests.

In general, feedback from users has been positive with general satisfaction with the electronic journal product. However, some individuals still preferring print over electronic access. The library has offered to do the downloading and printing on request to address these concerns. There is some insecurity about total coverage, i.e., is the electronic version the same as the print? There have also been updating problems with the most current issues not being available.

\section{Customer Case Study 3-Andrew Braid, Head of Publisher Liaison, The British Library}

Braid opened his presentation with a brief introduction to The British Library. The British Library is the national library of the U.K. and was founded in 1792 by an Act of Parliament. The Library's mission is to serve scholarship, research and innovation and to promote the advancement of knowledge through the communication of information and ideas. The Library has 2,415 staff and made over 10 million transactions in 1995/96 (5.5 million items consulted in its Reading Rooms and 4.5 million requests satisfied remotely). The Library's Strategic Plan for 1999/2000 placed a high priority on collecting digital materials and developing digital library services for reading room access and remote supply. The Library's Document Supply Center (BLDSC) was founded in 1961 and has 700 staff. It serves 18,000 customers worldwide (an estimated 2 million end-users) and handled over 4 million requests in 1998/99. Ninety percent (90\%) of those requests 
were satisfied from its own stock. BLDSC services include photocopy service, loan service, and premium services such as urgent action (satisfies the request within $2 \mathrm{~h}$ ).

The Center has used a variety of full text retrieval mechanisms over the years. However, the Library's financial situation in 1998 necessitates a cut in the serials budget, in particular duplicate subscriptions. One decision was to implement ScienceServer which currently includes only Elsevier Science titles but will be expanded to include other content in the future. The material arrives on CD-ROM and is loaded into ScienceServer. They check the actual receipts in as individual issues and produce header information. They have an automated process which

matches the content to their holdings. Their primary problems include supply times and the quality problems (particularly poor quality printing).

The conference closed with an open forum/customer feedback session moderated by Pat Sabosik (Vice President and General Manager, ScienceDirect) and Eric de Wilde (Director of the Regional Sales Office for Europe, the Middle East and Africa, Elsevier Science).

\section{References}

[1] Hunter, K. Electronic Journal Publishing. D-Lib Magazine (July/August 1998) www.dlib.org. [2] McKay, SC. Initial Articles E-Business for E-journals; Article Pay-Per-View. NASIG Conference, Pittsburgh, PA., June 1999:11.

[3] Hunter, KA. Things that keep me awake at night. Against the Grain 9 (Feb. 1997):41.

[4] Sanville, T. Executive Director's Monthly Report - July. July 1999:9.

[5] Ohio State University Administrative Staff Conference Minutes, July 1999:19.

[6] http://www.ohiolink.edu/whats-new.html.

[7] http://www.ohiolink.edu/whats-new.html. 